\title{
artículos
}

\section{Al principio fue... Jesús recogiendo sus vestiduras y sus fuentes literarias de inspiración}

\author{
Antonio Rafael Fernández Paradas \\ Rubén Sánchez Guzmán \\ Investigadores vinculados a la UMA
}

\section{RESUMEN}

Hasta ahora el tema que nos ocupa, el de Jesús recogiendo sus vestiduras después de la flagelación, había partido de la consideración de su rareza dentro de la iconografía religiosa y de su carácter especialmente atípico en lo que se refiere a la imaginería pasionista. Se pretende aquí, establecer las relaciones iconográficas entre el modelo de estudio y aquellas fuentes literarias que lo inspiraron a lo largo de de los siglos, con el objetivo de ampliar su margen de producción mas allá de los límites de la Contrarreforma, y romper con la tradicional idea de Cristo recogiendo sus vestiduras versus barroco.

PALABRAS CLAVE: Jesús recogiendo sus vestiduras/ Flagelación/ Literatura mística/ Iconografía religiosa.

At the beginning was... the iconography of "Christ gathering his clothes" and its sources

\section{ABSTRACT}

The iconography of "Christ gathering his clothes" after the Flagellation is considered often a strange subject in the visual context of the Passion. This article studies literary and iconographical sources of this episode, before and after The Catholic Reform.

KEY WORDS: Christ gathering his clothes/ Flagellation/ Mystical Literature/ Sacred Iconography.

1. Al principio fue... las fuentes literarias y su relación con el modelo ICONOGRÁFICO.

"Desatado de la columna, tú caes en tierra, a causa de tu debilidad, estás tan rendido por la pérdida de tu sangre que no puedes sostenerte sobre tus pies. Las almas piadosas te contemplan arrastrándote sobre el pavimento, barriendo tu sangre con tu cuerpo, buscando, acá y allá tus vestimentas"

Álvarez de Paz, Meditaciones, 1620, p. 151.

"Querer estudiar cada uno de los grandes artistas de este tiempo, como si se tratase de individuos aislados, sin preguntarse lo que debían al pensamiento de la iglesia, sería estudiar los planetas sin saber que giran alrededor del Sol"'. Según la bibliografía publicada hasta el momento, nuestro modelo iconográfico debió ser el mejor resultado material de la Contrarreforma: los franciscanos y Álvarez de Paz dicen esto,

* FERNÁNDEZ PARADAS, Antonio Rafael: "Al principio fue... Jesús recogiendo sus vestiduras y sus fuentes literarias de inspiración", en Boletín de Arte n⿳ 32-33, Departamento de Historia del Arte, Universidad de Málaga, 2011-2012, págs. 251-263. Fecha de recepción: Diciembre de 2010.

1 MÂLE. Emile, El arte religioso de la Contrarreforma (1932). Madrid, Ediciones Encuentro, 2001, pg. 1 


\begin{tabular}{|c|c|}
\hline 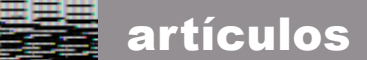 & Antonio Rafael Fernández Paradas \\
\hline
\end{tabular}

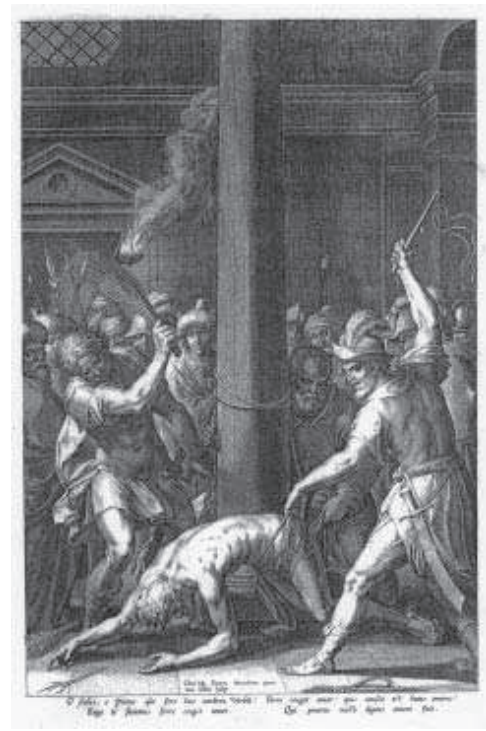

1. JOHAN SADELER I, 1550-1600: Flagelación, 1570-1600. $44.0 \times 29.2$ cm. Grabado a Buril. San Francisco (Estados Unidos de América), Museum of Fine Arts. Sobre cuadro perdido de Christoph Schwart.

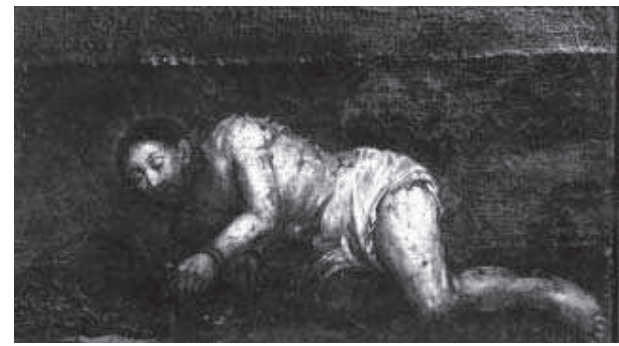

2. ANÓNIMO: Cristo recogiendo sus vestiduras, siglo XVII. $28 \times 48 \mathrm{~cm}$, óleo sobre lienzo. Brujas (Bélgica), Monasterio Agustino de Zwartzusters.

y estas son las obras que lo demuestran. Todo lo demás es rareza, Andalucía, Barroco y misticismo. Los autores que han tratado el tema hacen especial inca pie en lo barroco de la representación, tanto a nivel estilístico como cronológico, pero la Iglesia, no solo pensó durante la Contrarreforma, que lo hizo bastante, sino que hay todo un sustrato literario que llega desde el Medievo y enlaza directamente con la sociedad barroca. Nuestros místicos se entretenían leyendo viejos libros que andaban por

ahí amontonados, unas pocas mentes privilegiadas aportaban conocimiento nuevo (bibliometría), la mayoría vive de las rentas.

Sería absurdo no reconocer la importancia de según que obras, pero también lo es obcecarse en que solo esas tuvieron algo que decir. Al igual que hemos comprobado que las obras materiales conservadas son bastante más de las que se venían contando, con este trabajo pretendemos enriquecer el punto de vista de lo que nuestros pensadores, sean religiosos o Pacheco, podían manejar entre sus manos a la hora de crear nuevo conocimiento. Jesús recogiendo sus vestiduras después de la flagelación no fue un invento de los siglos XVII y XVIII, ya que desde la Edad Media el tema andaba latente en el ambiente. Literatura, poesía y tratados artísticos se hicieron eco del pasaje. Lo que sí aportó el periodo fue el concepto Barroco del espacio, movimiento y el punto de vista. Si no miramos más allá del Barroco, no cabría entender el grabado de Johan Sadeler I (1550-1600) [1], el lienzo conservado en el monasterio agustino de Zwarzusters, Brujas, o el relieve en piedra conservado en el Bayerlsches Nationalmuseum de Munich, entre otras, que se consideraban realizadas en el siglo XVI. Si tomamos como ejemplo la tela de Brujas [2], Ilama la atención 


理警 artículos $\quad$ La tensión paradójica, el límite seriado y los espacios ...

la "no" composición de lugar, hecho que demuestra que hubo vida antes de los Ejercicios Espirituales. De esta manera, si no entendemos el grabado de Baldung Grien [3], fechado en 1513, no podremos entender al antequerano Cristo del Mayor Dolor de Carvajal, realizado en 1771.

\subsection{LAS FUeNTES LITERARIAS DEL} MODELO.

Partiendo del hecho de que fue mucho y variado lo que se publico, con la siguiente relación se pretende ejemplificar obras representativas de diferentes periodos, autores y tendencias. Se han recogido pasajes de místicos, historias de la pasión, vidas de la Virgen y de los santos, revelaciones, poesía y tratados de

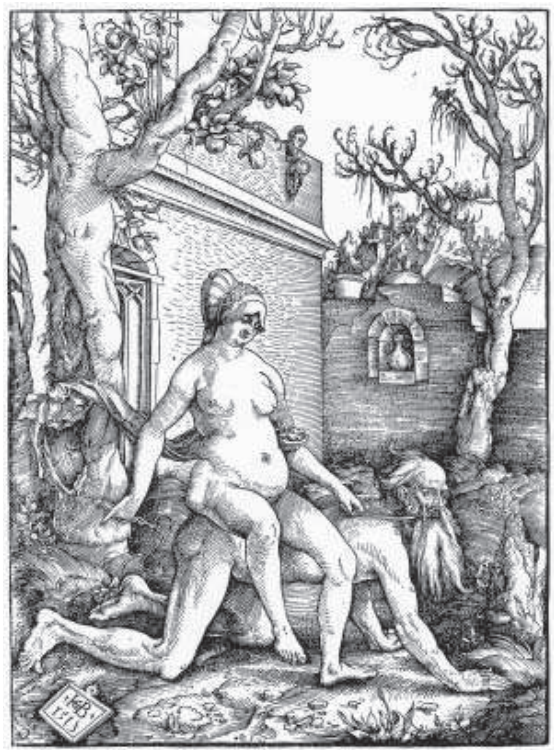

3. HANS BALDUNG GRIEN, 1484/5-1545: Filis y Aristoteles. iconografías. Hasta ahora ha sido una constante destacar que el tema no estaba recogido en las Sagradas Escrituras, quizá si lo estuviese sería el Espasa y no la Biblia.

Los pasajes que presentamos están ordenados por la fecha de la primera edición de la obra, según recoge Melquíades Andrés en su Historia de la Mística de la Edad de Oro en España y América y conforme al Palau². En el caso de Santa Brígida se recoge la fecha de compilación y edición por parte del Obispo Alfonso Pecha, no la de la primera edición latina, publicada en 1492. En algunos casos se ha consultado la primera edición; en otros, ediciones posteriores o alguna reproducción facsimilar. Tomamos también de Melquíades el número de ediciones de algunos ejemplares.

Recogemos 21 obras publicadas entre 1377 y 1800. De ellas 3 corresponden, si tomamos como referencia la primera edición latina de las Celestiales Revelaciones, al siglo XV; 8 al XVI; 9 al XVII y 1 al XIX. De ellas, 9 fueron publicadas antes de la primera edición de los Ejercicios Espirituales de Ignacio de Loyola en 1548. La publicación, en 1605, de las Meditaciones de los Misterios de Nuestra Santa Fe de Luís de la Puente, iba precedida de 11 obras que reseñaban el momento en el que Jesús recoge las vestiduras. La publicación de la obra de Álvarez de Paz contaba con

2 Manual del librero hispanoamericano: bibliografía general española e hispano-americana desde la invención de la imprenta hasta nuestros tiempos : con el valor comercial de los impresos descritos de Antonio Palau y Dulcet. 
14 precedentes. De las obras recogidas, por lo menos cuatro fueron auténticos "best seller", según Melquíades Andrés. Del Retablo de la vida de Christo fecho en metro por un deuoto frayle de la Cartuxa (1506), de Juan de Padilla, impreso en Sevilla, se editaron más de 15 ediciones; de la Subida al Monte Sión (1535), de Bernadino de Laredo, seis. El "Premio Planeta" se lo llevó Luís de la Puente, de su obra Meditaciones de los Misterios de nuestra Santa Fe (1605), se editaron más de 377 ediciones, en las lenguas más pintorescas: 35 ediciones en castellano completas y 46 en compendio; 108 en francés; 62 en italiano; 40 en latín; 34 en alemán; 8 inglés; 7 en portugués; 3 en bohemio; 27 en flamenco; 6 en polaco y 1 árabe. Es curioso destacar el hecho que el área germánica, Flandes y Polonia contasen en total con 70 ediciones. El morbo vende, el proceso inquisitorial abierto contra María Jesús de Agreda hizo que de su libro Mística ciudad de Dios (1670) se editasen mas de 30 ediciones. El siguiente cuadro resume brevemente el contenido de los pasajes literarios:

\begin{tabular}{|c|c|}
\hline \multicolumn{2}{|c|}{ RESUMENDE CONTENIDO DE LOS PASAJES LITERARIOS. } \\
\hline Lugar donde se desarrolla la escena & $\begin{array}{l}\text { 1495. Pedro Jiménez de Pregano }{ }^{3} \text {. Casa } \\
\text { 1499. San Buenaventura }{ }^{4} \text {. Casa } \\
\text { 1651. Martín de la Madre de Dios }{ }^{5} \text {. Sala o patio } \\
\text { 1659. San Buenaventura } 6 \text {. Palacio. }\end{array}$ \\
\hline $\begin{array}{l}\text { Condiciones Climatológicas. } \\
\text { Sensación de Frío }\end{array}$ & $\begin{array}{l}\text { 1495. Pedro Jiménez de Pregano } \\
\text { 1499. San Buenaventura } \\
\text { 1535. Bernardino de Laredo }^{9} \\
\text { 1670. María Jesús de } \text { Agreda }^{10}\end{array}$ \\
\hline $\begin{array}{l}\text { Espectadores que realmente } \\
\text { contemplaron la escena }\end{array}$ & $\begin{array}{l}\text { 1590. Juan Basilio Santero } \\
\text { 1652. Alonso Villegas }{ }^{12}\end{array}$ \\
\hline
\end{tabular}

3 JIMÉNEZ DE PREJANO, Pedro: Lucero de la vida cristiana. Burgos, Fadrique [Biel] de Basilea, 1495, pg. 68.

4 BuenaVenturA, San/ PSEUdo-BuenaVenturA (1499): Meditaciones de Passione lesu Christi, en Contemplación de la Vida de Ntro. Sr. Jesucristo... dispuesta por San Buenaventura. Madrid, 1824, pgs. 266267.

5 MADRE DE DIOS, Martín de la: Estaciones del Hermitaño de Cristo dedicadas a los padres hermitaños carmelitas descalços del santo desierto del Monte Cardón. Zaragoza, 1651, pg. 247.

6 BUENAVENTURA, San/ PSEUDO-BUENAVENTURA: Meditaciones de San Buenaventura sobre la Passion de Nuestro Salvador Jesu Christo. Brusselas, 1659, pgs. 137-138.

7 cfr. JIMÉNEZ DE PREJANO, Pedro, op. cit., pg. 68.

8 cfr. BUENAVENTURA, San/ PSEUDO-BUENAVENTURA, op. cit., 1824, pgs. 266-267.

9 LAREDO, Bernardino de (1535): Subida al Monte Sión. Madrid, Fundación Universitaria Española, 2001. pg. 271.

10 ÁGREDA, Ma Jesús de, (1670): Mística Ciudad de Dios, milagro de su omnipotencia y abismo de su gracia. Historia divina y vida de la Virgen Madre de Dios. Madrid, 1888, libro VI, capítulo 20, pg. 293.

11 SANTERO, Juan Basilio: La pasión del señor en siete estaciones. Pamplona, 1590, estación V. pg. 85 12 VILLEGAS, Alonso de: Historia general de la vida y hechos de Jesu-Christo... y de todos los santos de que reza y haze fiesta la Iglesia Catolica...: junto con las vidas de los santos propios de España y de otros extravagantes. Madrid, Melchor Sánchez, 1652, pg. 57. 


\begin{tabular}{|c|c|}
\hline Hecho de desatar a Cristo & $\begin{array}{l}\text { Recogido por la mayoría de los autores } \\
\text { 1551. Antonio Aranda }{ }^{13} \text {. Resalta como le desatan } \\
\text { los pies }\end{array}$ \\
\hline $\begin{array}{l}\text { Pasajes en los que se le indica que } \\
\text { se vista. }\end{array}$ & $\begin{array}{l}\text { 1526. Francisco Sánchez del Campo } \\
\text { 1551. Antonio de Aranda } \\
\text { 1590. Juan Basilio Santero } \\
\text { 1623. Tratado de Devotísimas y muy lastimosas } \\
\text { contemplaciones...17 } \\
\text { 1651. Martín de la Madre de } \text { Dios }^{18} \\
\text { 1670. María Jesús de Agreda }\end{array}$ \\
\hline $\begin{array}{l}\text { Pasaje en los que "busca" las } \\
\text { vestiduras" }\end{array}$ & $\begin{array}{l}\text { 1495. Pedro Jiménez de Prejamo }{ }^{20} \\
\text { 1499. San Buenaventura }{ }^{21} \\
\text { 1506. Juan de Padilla }{ }^{22} \\
\text { 1609. Francisco Pacheco }{ }^{23} \\
\text { 1652. Alonso Villegas }{ }^{24}\end{array}$ \\
\hline $\begin{array}{l}\text { Pasajes en los que se "agacha", } \\
\text { "inclina" o "recoge las vestiduras }\end{array}$ & $\begin{array}{l}\text { 1512. San Buenaventura }{ }^{25} \\
\text { 1526. Francisco Sánchez del Campo }{ }^{26} \\
\text { 1605. Félix Lope de Vega }{ }^{27} \\
\text { 1623. Tratado de Devotisimas y muy lastimosas } \\
\text { contemplaciones... }{ }^{28}\end{array}$ \\
\hline $\begin{array}{l}\text { Pasajes en los que "cae" a tierra o } \\
\text { se "arrastra" }\end{array}$ & $\begin{array}{l}\text { 1605. Luís de la Puente }{ }^{29} \\
\text { 1619. Diego Álvarez de Paz } \\
\text { 1652. Alonso Villegas }{ }^{31}\end{array}$ \\
\hline $\begin{array}{l}\text { Autores que solo indican que se } \\
\text { viste }\end{array}$ & $\begin{array}{l}\text { 1377. Santa Brígida }{ }^{32} \\
\text { 1501. Gonzalo de Ocaña }{ }^{33} \\
\text { 1533. Pedro de Alcantara }\end{array}$ \\
\hline Autores que inciden en la sangre & $\begin{array}{l}\text { 1377. Santa Brígida }{ }^{35} \\
\text { 1495. Pedro Jiménez de Prejano }{ }^{36} \\
\text { 1603. Luís de la Puente }{ }^{37} \\
\text { 1619. Alonso Villegas }{ }^{38}\end{array}$ \\
\hline $\begin{array}{l}\text { Autores que recogen la prohibición } \\
\text { de que se lave las heridas }\end{array}$ & 1533. Pedro del Alcántara ${ }^{39}$ \\
\hline $\begin{array}{l}\text { Pasajes en los que se indica que le } \\
\text { quitan las vestiduras de las manos y } \\
\text { juegan con ellas }\end{array}$ & $\begin{array}{l}\text { 1651. Gonzalo de Ocaña } \\
\text { 1670. María Jesús de Agreda }{ }^{41}\end{array}$ \\
\hline Hechos varios & $\begin{array}{l}\text { 1501. Gonzalo de Ocaña }{ }^{42} \text {. Enlaza el hecho con la } \\
\text { coronación de espinas. } \\
\text { 1609. Francisco Pacheco. "Por evitar la fealdad } \\
\text { o desgracia de estar muy baxa la figura, usé de } \\
\text { medio en que levantase con el cuerpo la ropa" } \\
\text { 1659. San Buenaventura. Arrastran a Cristo }{ }^{43} \\
\text { 1670. María Jesús de Agreda }{ }^{44} \text {. La Virgen } \\
\text { intercede. }\end{array}$ \\
\hline
\end{tabular}


Una primera consideración a tener en cuenta es dónde se desarrolla la escena, y en qué condiciones $Y$, además ¿Que elementos aparecen en ella? De la muestra de autores recogidos, sólo cuatro, dos en el siglo XV y dos en el XVII, dan una breve reseña del lugar donde se desarrolla la escena: los dos primeros hacen referencia a una casa; el tercero, a una sala o patio y Buenaventura, a un Palacio. De manera directa o indirecta, se cita la Columna y los sayones. Sólo con María Jesús de Agreda en 1670 aparecen los ángeles, la Virgen y el demonio. Desde 1495 aparecen expresiones como "mírale", y a lo largo de los siglos XVI y XVII la locución general será "contempla ánima".

13 ARANDA, Antonio de: Loores del dignissimo Lugar de Calvario : en que se relata todo lo que nuestro redemptor Jesus hizo y dixo en el, conforme al texto del sacro euangelio, perteneciente a su passion, muerte, sepultura y resurrection. Alcalá de Henares, 1551, pg. $169 \mathrm{v}^{\mathrm{a}}$.

14 SÁNCHEZ DEL CAMPO, Francisco: Tratado de deuotissimas muy lastimosas cotemplaciones de la passio del hijo de dios: compassion de la virgen sancta maria su madre Por esta razon llamado Passio duorum. Con las horas de la misma passion deuotissimas muy breues. Valladolid, 1526, pg. $94 \mathrm{v}^{\mathrm{a}}$.

15 cfr. ARANDA, Antonio de, op. cit., pg. 169 va

16 cfr. SANTERO, Juan Basilio. op. cit., pg. 85.

17 ANÓNIMO: Tratado de Devotisimas y muy lastimosas contemplaciones de la Pasión del hijo de Dios, y de la compasión de la Virgen Santa María su madre, por esta razón llamado Pasió Duoru. Madrid, 1623, p. 156

18 cfr. MADRE DE DIOS, Martín de la, op. cit., pg. 247.

19 cfr. ÁGREDA, Ma Jesús de, op. cit., pg. 293.

20 cfr. JIMÉNEZ DE PREJANO, Pedro, op. cit., pg. 68.

21 cfr. BUENAVENTURA, San/ PSEUDO-BUENAVENTURA, op. cit., 1824, pgs. 266-267.

22 PADILLA, Juan de, Retablo de la vida de Christo fecho en metro por un deuoto frayle de la Cartuxa (1506), Valencia, Vicent García, 2005, pg. 54.

23 PACHECO, Francisco, Arte de la pintura, (1649), Edición de Sánchez Cantón, Francisco José. Madrid, Instituto Valencia de don Juan, 1956, pg. 287-96

24 cfr. VILLEGAS, Alonso de, op. cit., pg. 57.

25 cfr. BUENAVENTURA, San/ PSEUDO-BUENAVENTURA (1512): Contemplación de la Vida de Ntro. Sr.

Jesucristo desde Su Concepción hasta la venida del Espíritu Santo. Madrid, 1824.pg. 269.

26 cfr. SÁNCHEZ DEL CAMPO, Francisco, op. cit., pg. 94 va.

27 LOPE DE VEGA, Felix (h. 1605): Los cinco Misterios Dolorosos. Edición, estudio y notas de César Hernández Alonso. Madrid, Instituto de Estudios Madrileños, 1987, pgs. 50-51

28 cfr. ANÓNIMO, op. cit., pg. 156.

29 PUENTE, Luis de la: Meditaciones de los misterios de nuestra santa fe, con la practica de la oración mental sobre ellos. Valladolid, Juan de Bostillo, 1605, t. II, meditación XXXV, pg.213.

30 ÁLVAREZ DE PAZ, Diego (1619): Opera Omnia. Lyon, 1623, t. III, meditación XIV, párrafo 5, col. 716-17.

31 cfr. VILLEGAS, Alonso de, op. cit., pg. 57.

32 BRÍGIDA DE SUECIA, Santa: Celestiales revelaciones de Santa Brigida Princesa de Suecia. Madrid,

1901, libro I. revelación 9, págs. 49-50. Las palabras de la Santa son recogidas casi literalmente por Luis de la Palma, Historia de la Sagrada Pasión. Madrid, 1967, pgs. 197-98.

33 OCAÑA, Gonzalo de: La vida de nuestro señor jesuchristo y de su santisima madre y de los otros santos según la orden de sus fiestas. Zaragoza, 1501, pg. $85 \mathrm{v}^{\mathrm{a}}$.

34 PEDRO DE ALCÁNTARA, San (1533): Tratado de la Oración, Meditación y Devoción. Madrid, 1731, pg. 130.

35 cfr. BRÍGIDA DE SUECIA, Santa, op. cit., pgs. 49-50.

36 cfr. JIMÉNEZ DE PREJANO, Pedro, op. cit., pg. 68.

37 cfr. PUENTE, Luis de la, op. cit., pg. 213.

38 cfr. VILLEGAS, Alonso de, op. cit., pg. 57.

39 cfr. PEDRO DE ALCÁNTARA, San, op. cit., pg. 130.

40 cfr. OCAÑA, Gonzalo de, op. cit., pg. 85 va .

41 cfr. ÁGREDA, Ma Jesús de, op. cit., pg. 293.

42 cfr. OCAÑA, Gonzalo de, op. cit., pg. $85 v^{\mathrm{a}}$.

43 cfr. BUENAVENTURA, SAN/ PSEUDO-BUENAVENTURA, op. cit., 1659, pgs. 137-138.

44 cfr. ÁGREDA, Ma Jesús de, op. cit., pg. 293. 
A nivel literario contrasta la economía de medidos con la que se construye la escena, a diferencia de las fuentes grabadas y materiales conservadas, con apelaciones, 10 en total, hacia el espectador/lector al que se introduce en la obra para que presencie y haga propio el dolor y sufrimiento del Señor. En relación a esto, serán una constante las inscripciones en los grabados y telas que nos hagan parte de la austera escenografía donde Jesús recoge sus vestiduras. Juan Basilio Santero, en 1590, y Alonso Villegas, en 1652, se saltan el hecho literario y enlazan sus obras directamente con el hecho real: " $y$ según conjeturan algunos contemplativos", y "dizenlo algunos contemplativos". Cuatro autores, en tres siglos diferentes, hacen referencia a las condiciones climatológicas. El énfasis en la sensación de frío permite crear mayor dramatismo en la escena, da pie a resaltar hechos relacionados con la sangre y las llagas y sitúa al "alma contemplativa" en una posición preferente respecto al Nazareno.

La mayoría de los autores tratados recogen el hecho de desatarle las manos, pero en 1551, Antonio Aranda se centra el hecho de como le desatan lo pies y tiene fuerzas para levantarse, lo cual no tiene precedentes en las obras tratadas.

Tenemos dónde y en qué condiciones climatológicas se desarrolla la escena, los espectadores directos y las ánimas que contemplan el drama. Sólo nos falta el protagonista, y es aquí donde vienen los matices. Que Jesús recoge sus vestiduras es un hecho, y lo hace desde antiguo. Cinco son las posibilidades que la construcción del momento, según la literatura ha dado de sí: autores que reseñan como a Cristo se le indica que se vista; autores que sólo indican que se viste; pasajes en los que "busca" las vestiduras; textos en los que se "inclina", "agacha" o "recoge"; y aquellas obras en las que Cristo "cae a tierra" y se "arrastra", normalmente sobre su propia sangre.

Los dos primeros matices, el hecho que le indiquen que se vista y que lo haga sin que nadie se lo mande, hacen suponer que una vez desatado, se levante o no, tuvo que realizar el acto físico. Como consecuencia se establece un punto de inicio sobre el que algún artista pudo partir. Aún así, una cosa es suponer que "hace algo" y otra es leer de manera expresa que "busca" algo. Mientras que se demuestre lo contrario, Jesús se viste desde 1377, pero "busca" sus vestiduras, hasta donde sabemos de momento, desde 1495. También "busca" en 1499, 1506 y 1609. Los años finales del XV y principios del XVI fueron propensos a "buscar", y curiosamente la obra de Juan de Padilla (1506), fue uno de los "best seller" del momento y la primera en la que literalmente "busca" sus vestiduras. Pero si una cosa es buscar en abstracto, otra lo es que Cristo se "agache", "incline" o "recoja" las vestiduras. El artista antes se movía en el mundo de las posibilidades, ahora sabemos que Cristo está relativamente cerca de suelo. La obra de San Buenaventura Contemplacion de la Vida de Ntro. Sr. Jesucristo desde Su Concepcion hasta la venida del Espiritu Santo (1512) se sitúa como la primera en la qué Jesús recoge sus vestiduras: "contempla aquella inmensa, é incomprensible majestad de Rey de Reyes como se baja y se inclina a la tierra, coge sus vestiduras, y se vuelve a vestir con grandísima vergüenza, y pudor". Francisco de Sánchez del Campo estará en esta misma línea, siendo también esta figura el motivo de inspiración para el poema "Los cinco Misterios Dolorosos" de Lope de Vega. 
Si hasta ahora no hay una mención expresa de cómo está representada la figura de Cristo, la carta de Pacheco fechada el 13 de octubre de 1609 supone todo un precedente iconográfico: "por evitar la fealdad o desgracia de estar muy baxa la figura, usé de medio en que levantase con el cuerpo la ropa”. ¿Se refiere acaso al modelo que esta arrodillado?

El quinto y último de los matices que señalamos era aquel en el que se establece que Cristo "cae a tierra" y se "arrastra" sobre su propia sangre. Junto con lo dicho por Pacheco son los dos únicos momentos en los que realmente se asienta un punto de inicio iconográfico. Archiconocidas y publicadas son las obras de Luís de la Puente (otro de los "best seller" del momento) y Diego Álvarez de Paz, de 1605 y 1619 respectivamente. Añadimos a Alonso Villegas (1652), que presenta pocas diferencias con respecto a los anteriores. Las obras de los Jesuitas son presentadas como el paradigma de la manifestación artística de la "composición de lugar" ignaciana, en ellas se fusionaba la composición de lugar previa a la meditación con la meditación misma, dando como resultado un texto sumamente visual. Así se explica el éxito obtenido entre los fieles, además de su interés cómo fuente iconográfica de creación de nuevos temas o variantes de los ya existentes.

\subsection{De Los orígenes fRANCISCANOS A LA difusión Jesuita.}

Alguien dijo que el Manierismo era un arte intelectualizado, mientras que el Barroco afectó al modo de vida de todas las capas sociales. Por consiguiente podemos hablar de una sociedad barroca, pero no de una sociedad manierista. Nuestro referente es qué dicen nuestros autores, cómo lo dicen y qué efectos produjeron sobre las obras físicas. Si miramos más allá y ojeamos sus biografías, dos son las cuestiones que nos llaman la atención: el afán viajero y la relevancia social de muchos de ellos, inmersos en los círculos intelectuales de las épocas en las que les toco vivir. Si afirmamos como consecuencia de esto, que Jesús recogiendo sus vestiduras después de la flagelación es una manifestación artística intelectualizada, y el arte intelectualizado es un arte de minorías, quedaría justificado el difícil acceso que muchas de las obras conservadas han tenido y la "rareza" del referente iconográfico en la Historia del Arte. Y quizás ese afán viajero, conllevó que nuestros escritores llevasen consigo ejemplares de sus amados libros, y que quizás los fueron dejando por el mundo, y con un poco de suerte cayeron en mano del algún artista deseoso de romper moldes. Los grabaditos hicieron el resto. Curioso es el hecho de que muchos de los grabados, telas y esculturas salieron de las manos de los más afamados artistas, algunos de ellos agentes de la vida política y social de la época en la que vivieron: Sadeler (1550-1600); Francisco Pacheco (1564-1644); Juan de Roelas (h. 1558/60-1615); Alonso de Mena y Escalante (1587-1646); Cornellis Galle (1576-1675); Antonio Arias (1614-1684); Bartolomé Esteban Murillo (1617-1682); Bocanegra (1638-1689); José de Mora (1642-1724); Diego de Mora (1658-1729); Andrés de Carvajal y Campos (1709-1779), etc. 
Citaremos algunos ejemplos de la vida social tan intensa que llevaron nuestros creadores. Pedro Jiménez de Prejano (h.1420-1495), entre otras muchas cosas, fue catedrático de la Universidad de Salamanca, Canónigo de Toledo, cronista oficial de Enrique IV. También acompañó al Cardenal Cisneros en la toma de Málaga y Obispo de Badajoz y Coria. San Pedro de Alcántara fue fundador de la Orden de los Alcantarinos y Consejero de Juan III de Portugal. Antonio de Aranda estuvo en una Misión Francisca en Jerusalén. Juan Basilio Santoro fue canónigo de la Catedral de Calahorra. Lope de Vega es uno de los Grandes del siglo de Oro; Pacheco, el tratadista español por excelencia; Diego Álvarez de Paz fue rector del Colegio Jesuita de Quito y Cuzco y Primer director del Colegio del Príncipe. Alonso Villegas publicó "Comedia Selvagia", que imita a la celestina y María Jesús de Ágreda, que se libró de la Inquisición, fue la consejera de Felipe IV.

Hasta 1551, por lo menos cuatro franciscanos recogieron en sus escritos la escena en la que Jesús recoge sus vestiduras, hay que recordar que la Subida al Monte Sión de Bernadino de Laredo tuvo seis ediciones. Habrá que esperar hasta 1670 para encontrar otra publicación en la estela de las de los franciscanos, será la obra de María Jesús de Agreda, perteneciente a la Orden de la Inmaculada Concepción. El Retablo de la Vida de Cristo (1506) del cartujo Juan de Padilla, con sus más de 15 ediciones, quizás sea la obra más estrechamente relacionada con los textos jesuitas del XVII. En general el texto de Padilla, y en concreto el pasaje de Jesús recogiendo sus vestiduras, se presentan como un perfecto manual para búsqueda de Dios en la soledad que propugnan los seguidores de San Bruno. Órdenes como los Jerónimos y los Carmelitas Descalzos, contaron también entre sus teólogos, Gonzalo de Ocaña (1501) y Martín de la Madre de Dios (1651) respectivamente, con partidarios de la causa.

Si en la primera mitad del siglo XVI la representación del Cristo es de clara raíz franciscana, la segunda mitad de la centuria vendrá marcada por el creciente protagonismo de los Jesuitas. En la orientación del tema un cúmulo de circunstancias variadas relacionan a Jesús recogiendo sus vestiduras después de la flagelación con la Compañía de Jesús. La primera de ellas sería lo propenso del tema a ilustrar la composición ignaciana de lugar.

En la Sevilla de la primera mitad del XVII proliferaron los más selectos cenáculos donde los eruditos locales, provenientes del clero, de la nobleza o del mundo artístico, daban un lustre cultural a la ciudad. Celebres eran las reuniones que organizaba el duque de Alcalá de Guadaira en su palacio de la Casa Pilatos o el poeta Juan de Arguijo en su casa de la calle Laraña, por donde pasó lo más granado de las artes, como el pintor Francisco Pacheco, el grabador Juan de Jauregui, y personajes del ambiente eclesiástico, como el deán de la catedral Vázquez de Leca. En ellos se intelectualiza acerca de teología, arqueología, historia, arte o poesía. Muy vinculada a este grupo se encontraba desde un principio la orden Jesuita: Jauregui estudió con ellos en el colegio de San Hermenegildo; Juan de Arguijo después de su ruina económica se refugió en la profesa y Pacheco, con tan solo 16 años y recién llegado a Sevilla, tomó al jesuita Gaspar de Zamora como confesor y director espiritual. Como 
ha señalado Gutiérrez de Cevallos (2002), la casa de los Arguijo se encontraba frente por frente con los edificios de la profesa y bastaba cruzar la calle para que Pacheco se trasladase a dialogar con sus amigos los jesuitas sobre cuestiones de toda índole, incluidas las teológicas, artísticas e iconográficas, que le ayudaran a componer su Arte de la Pintura.

Según Mâle, "Álvarez de Paz no solo era leído en España. En Flandes se conocían sus meditaciones, como lo demuestra el emocionante dibujo de Van Diepenbeeck, grabado por Cornelius Galle"45. Más adelante el mismo auto recoge: "Los jesuitas, a menudo, hicieron representar su vida (la de San Iganacio). En su casa de Alcalá de Henares, quince cuadros de Juan de Mesa, la contaban enteramente, según la biografía de Ribadeneira. En la Orden este libro tenía una especie de carácter canónico $y$, en 1610, los Padres lo hicieron ilustrar en Amberes por muchos artistas flamencos, siendo los principales Cornelius y Théodore Galle. Estos grabados, publicados aparte, formaban un pliego que se extendió por Europa y sirvió de modelo temático a los artísticas" 46 . Conforme a esto, podríamos especular que los grabados representando a Jesús recogiendo las vestiduras que fueron realizados por Galle podrían haber sido un encargo directo de los Jesuitas. Lo que no recoge Mâle son las mas 377 ediciones de las Meditaciones de los Misterios de nuestra Santa Fe de Luís de la Puente, ni las 27 traducidas al flamenco, pero quizás sean estas las que realmente influyeron en los artistas. Otro hecho que sitúa a los Jesuitas a la cabeza de la difusión del modelo iconográfico durante los siglos XVII y XVIII, en este caso por Sudamérica, fue el viaje y asentamiento de Álvarez de Paz por aquellas tierras. Esto podría ser una explicación a la cantidad de representaciones conservadas en varios países del nuevo continente, algunas de ellas en ciudades en las que el Jesuita estuvo.

Analizadas las obras conservadas, vemos que, desde muy pronto los artistas tuvieron un modelo literario fiel que seguir. Además desde comienzos del siglo XVII, hay varios modelos iconográficos establecidos. Si la primera mitad del XVI viene marcada por la hegemonía franciscana, la segunda mitad y el siglo XVII lo estarán por el triunfo de los ideales Jesuitas. A nivel literario podemos afirmar que Jesús recogiendo sus vestiduras después de la flagelación contó con precedentes desde finales del siglo $\mathrm{XV}$, y que algunas de las obras tratadas, básicas en la configuración del tema, fueron verdaderos éxitos de ventas.

"Tú que pasas, mírame: contempla un poco en mi llagas y verás qué mal me pagas la sangre que derramé" 47 .

45 cfr. MÂLE. Emile, op. cit., pg. 248.

46 cfr. MÂLE. Emile, op. cit., pg. 413

47 VEGUE Y GOLDINI. Ángel, Temas de Arte y Literatura. Madrid, 1958. pgs. 45 y ss 


\section{Bibliografía.}

AA.VV, Jesucristo y el emperador cristiano. Catálogo de exposición. Granada, Caja Sur, 2000.

ÁGREDA, Ma Jesús de, Mística Ciudad de Dios, milagro de su omnipotencia y abismo de su gracia. Historia divina y vida de la Virgen Madre de Dios (1670). Madrid, 1888,

ÁLVAREZ DE PAZ, Diego, De Inquisitione pacis sive Studio orationis. Lyon, 1617. ÁLVAREZ DE PAZ, Diego, Opera Omnia. Lyon, 1623.

ANDRÉS, Melquíades, Historia de la mística de la edad de oro en España y América. Madrid, La Editorial Católica, 1994.

ANDRÉS, Melquíades, Los místicos de la edad de oro en España y América: antología. Madrid, Biblioteca de Autores Cristianos, 1996.

ANDRÉS, Melquíades, Los recogidos: nueva visión de la mística española (1500-1700). Madrid, Fundación Universitaria Española, 1975.

ANÓNIMO, Tratado de Devotisimas y muy lastimosas contemplaciones de la Pasión del hijo de Dios, y de la compasión de la Virgen Santa María su madre, por esta razón llamado Pasió Duorum. Madrid, 1623.

ARANDA, Antonio de, Loores del dignissimo Lugar de Calvario: en que se relata todo lo que nuestro redemptor Jesus hizo y dixo en el, conforme al texto del sacro euangelio, perteneciente a su passion, muerte, sepultura y resurrection. Alcalá de Henares, 1551

BERMEJO Y CARBALLO (1882). José, Glorias Religiosas de Sevilla. Noticia histórico descriptiva de todas las cofradías de penitencia, sangre y luz, fundadas en esta ciudad. Sevilla, Editorial Castillejo, 1994.

BRÍGIDA DE SUECIA, Santa, Celestiales revelaciones de Santa Brigida Princesa de Suecia. Madrid, 1901.

BUENAVENTURA, San/ PSEUDO-BUENAVENTURA (1499), Meditaciones de Passione lesu Christi. En Contemplación de la Vida de Ntro. Sr. Jesucristo... dispuesta por San Buenaventura. Madrid, 1824

BUENAVENTURA, San/ PSEUDO-BUENAVENTURA (1512), Contemplación de la Vida de Ntro. Sr. Jesucristo desde Su Concepción hasta la venida del Espíritu Santo. Madrid, 1824.

BUENAVENTURA, San/ PSEUDO-BUENAVENTURA, Meditaciones de San Buenaventura sobre la Passion de Nuestro Salvador Jesu Christo. Brusselas, Francisco Foppens, 1659.

CAMÓNAZNAR. José, La Pasión de Cristo en el arte español. Serie Cristológica T. III. Madrid, Biblioteca de Autores Cristianos, 1949.

CEÁN BERMúDEZ. Juan Agustín (1800), Diccionario Histórico de los más ilustres profesores de las Bellas Artes en España. Madrid, Real Academia de Bellas artes de San Fernando y de la Historia, 1965.

ESCALANTE JIMÉNEZ, José, "El caudal del Santísimo Cristo del Mayor Dolor". Pregón, 1997. pp. 53-54.

GALLEGO BURÍN, Antonio (1925), José de Mora. Su vida y su obra,. Granada, 
Universidad de Granada, 1988.

GONZÁLEZ DE ZÁRATE, Jesús Maria y VANDERBROECK, Paúl, "Una nota sobre el tema de Murillo Cristo recoge las vestiduras”, Boletín Camón Aznar, LV, 1994 pp.55-60.

GONZÁLEZ GÓMEZ, Juan Miguel, "Una obra inédita de Lorenzo Cano. Jesús del Mayor Dolor de Écija”, Laboratorio de Arte, 13, Sevilla, 2000, págs. 193-206.

HATZFELD, Helmut, Estudios literarios sobre mística española. Madrid, Editorial Gredos, 1955.

INTERIAN DE AYALA. J, El pintor Cristiano y erudito, o tratado de los errores que suelen cometerse frecuentemente en pintar y esculpir las imágenes sagradas. Madrid, Joaquín Ibarra, 1782.

JIMÉNEZ DE PREJANO, Pedro, Lucero de la vida cristiana. Burgos, Fadrique [Biel] de Basilea, 1495.

JUAN DE LA CRUZ, San (1618), Subida al Monte Carmelo,. Madrid, Editorial de Espiritualidad, 1983.

LAREDO, Bernardino de (1535), Subida al Monte Sión. Madrid, Fundación Universitaria Española, 2001.

LOPE DE VEGA, Félix (h. 1605), Los cinco Misterios Dolorosos. Edición, estudio y notas de César Hernández Alonso. Madrid, Instituto de Estudios Madrileños, 1987,

LÓPEZ PLASENCIA, José Cesáreo, "Literatura Mística y piedad contrarreformista. La imagen de Cristo tras la flagelación en el arte español", Cuadernos de Arte e Iconografía, 32, Madrid, 2007. págs. 447-476.

MADRE DE DIOS, Martín de la (1651), Estaciones del Hermitaño de Cristo dedicadas a los padres hermitaños carmelitas descalços del santo desierto del Monte Cardón. Zaragoza, 1652.

MÂLE. Emile (1932), El arte religioso de la Contrarreforma. Madrid, Ediciones Encuentro, 2001.

MARTÍNEZ MEDINA, Francisco Javier, "Iconoteología del Cristo del Mayor Dolor". Miscelánea Augusto, 21, Segovia 1986, págs. 219-242.

MARTÍNEZ MEDINA, Francisco Javier, Cultura Religiosa en la Granada Renacentista y Barroca (Estudio Iconológico). Granada, Universidad de Granada, 1989.

MORENO GARCÍA, Juan Manuel, "Genealogía línea paterna del escultor Andrés de Carvajal y Campos (1709-1779)", Sol de Antequera, Especial Semana Santa 1997. Antequera, 1997.

MORENO VILLA. José, La escultura colonial mexicana. México, Colegio de México, 1942.

OCAÑA, Gonzalo de, La vida de nuestro señor Jesuchristo y de su Santísima madre y de los otros santos según la orden de sus fiestas. Zaragoza, 1501.

OROZCO DÍAZ, Emilio, "La literatura religiosa y el Barroco", Revista de la Universidad de Madrid, XI, 1962.

OROZCO DÍAZ, Emilio, "Unas obras de Risueño y Mora desconocidas", Archivo Español de Arte, 175, 1971. págs. 233-257.

PACHECO, Francisco, Arte de la pintura, (1649). Edición de Sánchez Cantón, 


\begin{tabular}{|c|c|c|}
\hline 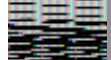 & articulos & La tensión paradójica, el límite seriado y los espacios ... \\
\hline
\end{tabular}

Francisco José. Madrid, Instituto Valencia de don Juan, 1956.

PADILLA, Juan de (1506), Retablo de la vida de Christo fecho en metro por un deuoto frayle de la Cartuxa. Valencia, Vicent García, 2005.

PALMA, Luís de la, "Historia de la Sagrada Pasión". en Anónimo: Obras completas del Padre Luis de la Palma. Madrid, Editorial Católica, 1967.

PEDRO DE ALCÁNTARA, San (1533), Tratado de la Oración, Meditación y Devoción. Madrid, 1731.

PIZANO, Roberto, Gregorio Vásquez de Arce y Ceballos. París Camilo Bloch, Editor, 1926.

PUENTE, Luis de la, Meditaciones de los misterios de nuestra santa fe, con la practica de la oración mental sobre ellos. Valladolid, Juan de Bostillo, 1605.

RAMAIX, Isabelle de, The Illustrated Bartsch Vol. 70 Part 4 Johan Sadeler I. New York, Abaris Book, 2004.

RÉAU, Louis, Iconografía del arte cristiano. Iconografía de la Biblia. Nuevo testamento. T. I, Volumen 2. Barcelona, Ediciones del Serbal, 2000.

RODRÍGUEZ G. DE CEBALLOS, Alfonso, "Fuentes iconográficas y literarias del cuadro de Velásquez "Cristo y el Alma Cristiana", Cuadernos de Arte e Iconografía, 1991, 8, págs. 82-90.

SAINZ RODRÍGUEZ, Pedro, Introducción a la historia de la literatura mística en España. Madrid, E. Voluntad, 1927.

SÁNCHEZ DEL CAMPO, Francisco, Tratado de deuotissimas muy lastimosas cotemplaciones de la passio del hijo de dios: compassion de la virgen sancta maria su madre Por esta razon llamado Passio duorum. Con las horas de la misma passion deuotissimas muy breues, Valladolid, 1526.

SÁNCHEZ LÓPEZ, Juan Antonio, "Imago Imaginis. Un ejemplo de propaganda visual bajo las ópticas popular y culta”, Baetica 17, 1995, págs. 31- 52.

SÁNCHEZ LÓPEZ, Juan Antonio, El alma de la madera. Cinco siglos de iconografía y escultura procesional en Málaga. Málaga, Hermandad de la Amargura, 1996, págs. 149-150.

SANTERO, Juan Basilio, La pasión del señor en siete estaciones. Pamplona, 1590.

SANZ VALDIVIESO, Rafael, Místicos franciscanos españoles. Madrid, Biblioteca de Autores Cristianos, 1996-1998. 2 Volúmenes.

SAXONIA, Ludophus a, Vita Jesé Christi. Paris, 1878.

VALDIVIESO, Enrique, Juan de Roelas. Col. Arte Hispalense, número 18. Sevilla, Diputación de Sevilla, 1978.

VILLEGAS, Alonso de, Historia general de la vida y hechos de Jesu-Christo... y de todos los santos de que reza y haze fiesta la Iglesia Catolica...: junto con las vidas de los santos propios de España y de otros extravagantes. Madrid, Melchor Sánchez, 1652. 
